PROFESIONALES Y HERRAMIENTAS PARA EL DESARROLLO LOCAL Y SUS SINERGIAS TERRITORIALES. EVALUACIÓN Y PROPUESTAS DE FUTURO IX Coloquio Nacional de Desarrollo Local del GTDL-AGE 

ANTONIO MARTÍNEZ PUCHE, XAVIER AMAT MONTESINOS, ISABEL SANCHO CARBONELL y DANIEL SANCHIZ CASTAÑO (EDS.)

\section{PROFESIONALES Y HERRAMIENTAS PARA EL DESARROLLO LOCAL Y SUS SINERGIAS TERRITORIALES. EVALUACIÓN Y PROPUESTAS DE FUTURO}

IX Coloquio Nacional de Desarrollo Local del GTDL-AGE

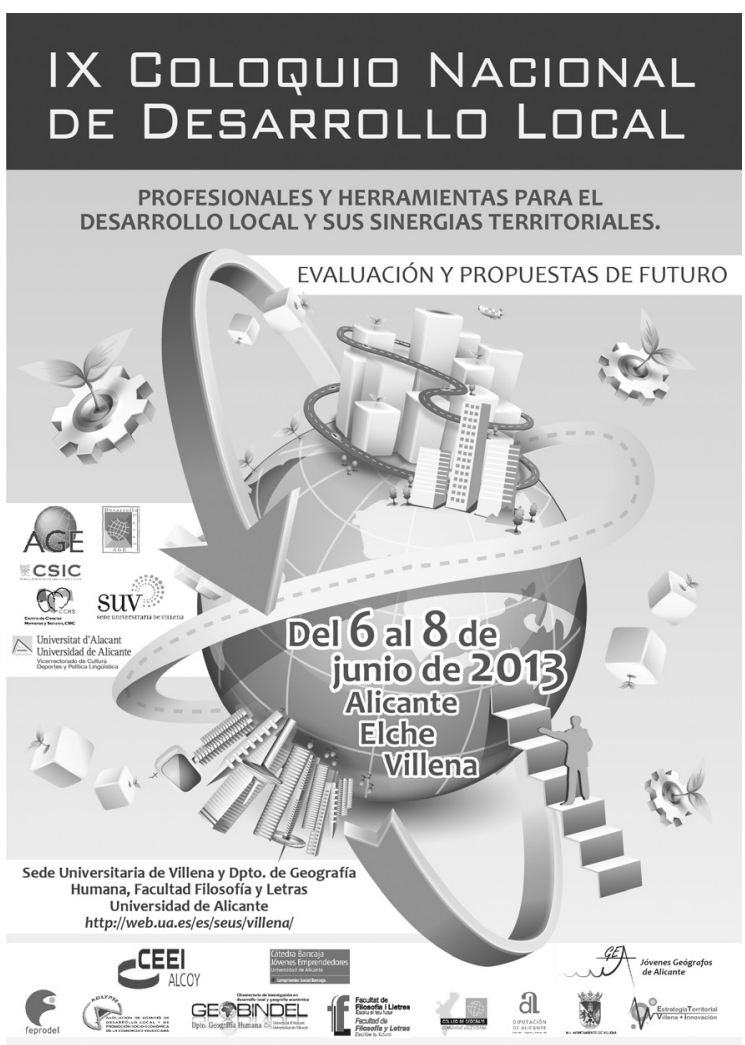


Este libro ha sido examinado y valorado por evaluadores ajenos a la Universidad de Alicante, con el fin de garantizar la calidad científica del mismo.

Publicacions de la Universitat d'Alacant

03690 Sant Vicent del Raspeig

Publicaciones@ua.es

http://publicaciones.ua.es

Telèfon: 965903480

(C) Antonio Martínez Puche, Xavier Amat Montesinos,

Isabel Sancho Carbonell y Daniel Sanchiz Castaño (eds.), 2016

(C) d'aquesta edició: Universitat d'Alacant

ISBN: 978-84-16724-00-0

Dipòsit legal: A 92-2016

Disseny de coberta: candela ink

Composició: Página Maestra (Miguel Ángel Sánchez Hernández)

Impressió i enquadernació: Guada Impresores

\section{unte \\ Unión de Editoriales
Universitarias Españolas \\ WWW.une.es
WWA}

Esta editorial es miembro de la UNE, cosa que garantiza la difusión y comercialización nacional y internacional de sus publicaciones.

Reservados todos los derechos. Cualquier forma de reproducción, distribución, comunicación pública o transformación de esta obra sólo puede ser realizada con la autorización de sus titulares, salvo excepción prevista por la ley. Diríjase a CEDRO (Centro Español de Derechos Repográficos, www.cedro.org) si necesita fotocopias o escanear algún fragmento de esta obra. 


\title{
METODOLOGÍAS AUTÁRQUICAS PARA EL DESARROLLO LOCAL
}

\author{
Eloy Sentana Gadea \\ Agencia Local de Desarrollo Ayuntamiento de Alicante \\ Eloy.Sentana@economialocal.com
}

RESUMEN

El conocido como periodo autárquico de la economía española, que abarcó entre los años 1941 y 1959, representó una etapa en la que se procuraba rehuir del abastecimiento exterior fundamentando todo el crecimiento en el autoconsumo. Analizaremos el concepto de autarquía desde una concepción moderna. Este ensayo se centrará en la comparación de los dos periodos con la finalidad de extraer conclusiones para superar una crisis como la actual en el corto plazo y siempre desde la perspectiva de los entes locales.

Palabras clave: autarquía, autoabastecimiento, comparación, crisis, crecimiento.

\section{AUTARKY STRATEGIES FOR THE LOCAL DEVELOPMENT}

\begin{abstract}
During the 'autarky period' of the Spanish economy, among 1941 and 1959, the developed strategy tried to avoid to bring rare materials and supplies overseas. The growth of the country was based on self-consumption. The concept of 'autarky' will be analysed on this article from a modern perspective. This essay is focused on a comparison between both periods in order to obtain useful conclusions to make proposals to beat a crisis like now in the short-term, from the point of view of the local governments.
\end{abstract}

Key words: autarky, self-consumption, comparison, crisis, growth. 


\section{Autarquía Postbélica y CRISIS actual}

Arrastramos una losa de más de seis millones de desempleados. Se desmantela la Administración a golpes de martillo presupuestario, a la vez que todas sus empresas y entidades paralelas, por económicamente insostenibles. No hay crédito para las empresas. La renta de las familias está cayendo vertiginosamente. Los recortes se han instaurado como la única acción posible (¿?). Hemos conocido una nueva figura de protesta social, los "escraches", dirigidos a los políticos, adocenados, para concienciarlos de la imperiosa necesidad de evitar los desahucios de quienes se hipotecaron en una época de bonanza pero a quienes la crisis ha dejado sin trabajo y sin ingresos para hacer frente a préstamos ahora inasumibles. La situación empeora por una multiplicidad de administraciones incapaces de coordinarse para llevar a cabo políticas eficaces que contribuyan a superar esta sensación de "bloqueo colectivo" en el que parece no hay nadie que con relativa certeza sepa qué hacer para resurgir de esta situación. El elemento más pernicioso es sin duda, el negativo impacto en la confianza en los ciudadanos y empresas, completando una ecuación aparentemente sin solución de: incertidumbre $=+$ retracción del consumo $=+$ desempleo, algoritmo que tan bien analiza (J.Shiller, 2009) en su libro "Animal Spirits".

La Unión de Ciudades y Gobiernos locales elaboró un documento (Locales, 2009) en el que se analizaban los efectos de la crisis en las entidades locales. Las principales conclusiones a las que llega el estudio son:

a) Cuando se les dan medios y la posibilidad de gestionar los recursos, los entes locales son eficaces para promover el empleo y la actividad económica.

b) La crisis ha puesto de manifiesto la endeble estructura descentralizada donde los entes locales son muy vulnerables a la caída de los ingresos propios, siendo muy dependientes de las transferencias de los gobiernos centrales y autonómicos.

c) La salida de la crisis debe prospectarse como un proyecto a medio y largo plazo, por lo que será necesario contemplar actuaciones que abarquen cada uno de estos periodos.

Ante esta falta de una 'hoja de ruta' clara y solvente, puede resultar clarificador echar la mirada atrás y encontrar referencias que aporten nitidez a una política descarriada por lo incierto de sus derroteros que siempre terminan recayendo sobre pymes y trabajadores. El motivo de elegir el periodo autárquico responde al resultado de una preliminar identificación a volapié de periodos históricos con un sustrato de crisis con un perfil similar al actual y efectos colaterales en los principales sectores de la economía. La proximidad en el tiempo definió la selección.

El motivo de esta propuesta es el de, a la vista de las características de la crisis actual, indagar en las posibilidades que tienen las entidades locales de abordar un planteamiento de reestructuración interna, con tintes autárquicos, 
como un medio eficaz para relanzar la economía, identificando qué características deben tener estas iniciativas. Se plantea, de un lado, contrastar la situación económica del final de la postguerra Civil, hasta 1959 (fecha en la que se aprueba e inicia el Plan Nacional de Estabilización) con las características de la crisis actual. Resultará de especial interés identificar las similitudes y diferencias existentes entre estos dos periodos y poder aplicarlo con las ventajas de nuestra experiencia y condiciones actuales.

Dos salvedades previas: En primer lugar, reseñar que es necesario realizar un ejercicio de abstracción sobre el entorno político en el que se analiza la idea primigenia de autarquismo; rescataremos las conexiones exclusivamente económicas, sin ignorar que la economía es un todo que aúna sociedad, capital, cultura y 'las circunstancias' de Ortega y Gasset. Por otra parte, la propuesta que surgirá en todo caso ha de enfocarse desde una línea de aplicación cortoplacista, habida cuenta de los nocivos efectos que tuvo este periodo económico postbélico y cuya prolongación devino en un distanciamiento de la competitividad del país respecto al resto de Europa. Entiendo, no obstante, que se podrán obtener efectos de interés para el corto plazo y de uso como mecanismo de crecimiento en entornos locales.

Comencemos analizando el estado en el que la guerra fraticida que tuvo lugar en nuestro país, dejó a la economía, que de forma resumida podríamos identificar como:

\section{Tabla 1. Cuadro comparativo situación económica Guerra Civil-actualidad}

\begin{tabular}{|l|l|}
\hline $\begin{array}{c}\text { Características de la economía española } \\
\text { tras la Guerra Civil (1941) }\end{array}$ & $\begin{array}{l}\text { Características de la economía española } \\
\text { en el momento actual (2013) }\end{array}$ \\
\hline $\begin{array}{l}\text { Proceso de destrucción material de infraes- } \\
\text { tructuras y centros de producción a con- } \\
\text { secuencia de la destrucción inherente a la } \\
\text { guerra y a al abandono del campo y fábricas } \\
\text { por quienes habían de acudir al frente. En } \\
\text { todo caso, esta pérdida de instalaciones fue } \\
\text { inferior a las de la Segunda Guerra Mundial. }\end{array}$ & $\begin{array}{l}\text { Se harial y fabril sin precedentes. Se han } \\
\text { levado a cabo aportaciones de capital (por } \\
\text { de la crisis en sectores considerados clave } \\
\text { que ha detraído capital de otros ámbitos em- } \\
\text { presariales y ha ahondado su declive. }\end{array}$ \\
\hline $\begin{array}{l}\text { A consecuencia de la guerra y la pérdida } \\
\text { de infraestructuras y empresas, se produjo } \\
\text { una caída de la renta per cápita de las fa- } \\
\text { milias. El nivel de } 1936 \text { no se recuperaría } \\
\text { hasta 1950. }\end{array}$ & $\begin{array}{l}\text { La pérdida de puestos de trabajo, el aumen- } \\
\text { to de impuestos, de los gastos corrientes } \\
\text { (agua, luz, combustibles,...) ha reducido la } \\
\text { capacidad de consumo de familias y empre- } \\
\text { sas, con una tasa de ahorro de sólo el 6,7\% } \\
\left(3^{\circ} \text { Trim.2012). }\right.\end{array}$ \\
\hline $\begin{array}{l}\text { Fuerte retroceso de la inversión y el consu- } \\
\text { mo privado. La producción de acero y hie- } \\
\text { rro fundido se reduce en un 50\% respecto } \\
\text { a 1929. }\end{array}$ & $\begin{array}{l}\text { La restricción de crédito impide a las em- } \\
\text { presas invertir en tecnología y maquinaria } \\
\text { que permita su crecimiento. }\end{array}$ \\
\hline
\end{tabular}




\begin{tabular}{|l|l|}
\hline $\begin{array}{c}\text { Características de la economía española } \\
\text { tras la Guerra Civil (1941) }\end{array}$ & $\begin{array}{l}\text { Características de la economía española } \\
\text { en el momento actual (2013) }\end{array}$ \\
\hline $\begin{array}{l}\text { Crecimiento de las obligaciones de pago } \\
\text { para cubrir las necesidades de la guerra. }\end{array}$ & $\begin{array}{l}\text { El endeudamiento de las familias, empresas } \\
\text { y administraciones públicas no ha conocido } \\
\text { cifras similares a las actuales. }\end{array}$ \\
\hline $\begin{array}{l}\text { Inflación (con aumento de hasta dos dígitos) } \\
\text { y depreciación monetaria, en su momento } \\
\text { posible por la inexistencia de un patrón mo- } \\
\text { netario unificado. }\end{array}$ & $\begin{array}{l}\text { El aumento de los precios se ha arbitrado } \\
\text { especialmente a través del aumento del IVA, } \\
\text { así como el encarecimiento de la vivienda, } \\
\text { que curiosamente no forma parte del IPC de } \\
\text { manera directa. }\end{array}$ \\
\hline $\begin{array}{l}\text { Pérdidas de capital humano muy importan- } \\
\text { tes (Exceso de mortalidad: 540.000 perso- } \\
\text { nas, déficit de natalidad 576.000 nacimien- } \\
\text { tos: más de 700.000 exiliados, muchos de } \\
\text { ellos combatientes del frente y por tanto, en } \\
\text { edad óptima de trabajar. }\end{array}$ & $\begin{array}{l}\text { La fuga de jóvenes titulados y trabajado- } \\
\text { res experimentados al extranjero es un he- } \\
\text { cho cotidiano. La pérdida no es sólo de las } \\
\text { personas, sino del coste que ha supuesto su } \\
\text { formación, fuertemente subvencionada por } \\
\text { el Estado. }\end{array}$ \\
\hline
\end{tabular}

Fuente: (Miranda, 2001) y Elaboración propia.

Una primera ojeada a ambos periodos no deja de causar cierta perplejidad por el cariz y similitud de estas impresiones. No obstante, y esto nos servirá para articular soluciones novedosas, no se puede obviar el hecho de que en una etapa como la actual contamos con elementos, tecnologías y capital humano principalmente, que permiten responder en otros ámbitos y, con toda seguridad, disponiendo de un mayor abanico de opciones que los que podían identificarse en la recién inaugurada etapa franquista.

En una segunda revisión, observamos que es precisamente el final de la guerra que felizmente ponía fin a la barbarie que costó la vida a más de medio millón de compatriotas de uno y otro bando. Pero a la vez fueron el punto de partida para aplicar políticas económicas que pretendían, a partir del autoconsumo y las restricciones a los intercambios con el exterior, lograr ilusoriamente reengancharse a la corriente de crecimiento que hasta aquel momento inundaba Europa. Pese a lo que se podía pensar, aquellas iniciativas no sólo se sustentaban bajo una ideología política que pretendía impregnar todo aquello que se articulaba bajo el nuevo régimen, sino que también se organizaba en torno a una situación de necesidad real: España estaba verdaderamente aislada de Europa, por lo que tampoco hubiera tenido sentido emprender una cruzada para estrechar lazos económicos con un entorno ciertamente hostil: el autoabastecimiento era pues, también necesidad. Y con esta posición se dio inicio al conocido como periodo autárquico que comprendería desde el final de la guerra Civil hasta el año 1959, en el que se aprueba el "Plan Nacional de estabilización". 
Las principales características del modelo autárquico fueron (Ligero, 2005) y su comparación con la situación actual:

\section{Tabla 2. Cuadro comparativo periodo autárquico}

\begin{tabular}{|c|c|}
\hline $\begin{array}{l}\text { Características del modelo autárquico } \\
\qquad(1940-1959)\end{array}$ & Analogía con la situación actual \\
\hline $\begin{array}{l}\text { Cierre del mercado interno mediante la pro- } \\
\text { tección arancelaría que evoluciona hacia } \\
\text { un proteccionismo integral. Modelo que se } \\
\text { abre parcialmente al exterior en } 1959 \text {, con } \\
\text { vestigios hasta } 1985 \text {, con la entrada en la } \\
\text { CE. }\end{array}$ & $\begin{array}{l}\text { El consumo interno está paralizado, entre } \\
\text { otras cuestiones, por una reducción del cré- } \\
\text { dito y por un alza de impuestos (IVA, reduc- } \\
\text { ción de la renta disponible vía aumento de } \\
\text { costes vía estructuras }\end{array}$ \\
\hline $\begin{array}{l}\text { Inexistencia de una política que garantiza- } \\
\text { se la estabilidad de los precios y del tipo } \\
\text { de cambio. Regulación discrecional de la } \\
\text { actividad económica. Intervencionismo en } \\
\text { los mercados y las decisiones de los agentes } \\
\text { económicos, alejándolos de la liberaliza- } \\
\text { ción y la competencia. }\end{array}$ & $\begin{array}{l}\text { Se produce, de facto, un intervencionismo } \\
\text { y de las decisiones, a través de las "orien- } \\
\text { taciones obligatorias" de la UE respecto a } \\
\text { las políticas del mercado de trabajo, fiscali- } \\
\text { dad, jubilación y de subsidio bancario, entre } \\
\text { otras. }\end{array}$ \\
\hline $\begin{array}{l}\text { Importante presencia de la economía su- } \\
\text { mergida, sobre todo en materias primas, } \\
\text { acrecentada por el aumento de controles y } \\
\text { el establecimiento de precios desde el Es- } \\
\text { tado. Falsificación sistemática de los valo- } \\
\text { res declarados en aduanas con la finalidad } \\
\text { de disponer de divisas en el extranjero para } \\
\text { importar bienes o cambiarlas en el mercado } \\
\text { negro. Uso del mercado negro por parte de } \\
\text { turistas. }\end{array}$ & $\begin{array}{l}\text { Aumento de las transacciones en dinero 'B' } \\
\text { como consecuencia de un mayor control so- } \\
\text { bre las transacciones económicas y un au- } \\
\text { mento del gravamen sobre las actividades a } \\
\text { través de la imposición indirecta (IVA). Pro- } \\
\text { liferación de activos (viviendas) cuyo precio } \\
\text { de adquisición fue superior al declarado. }\end{array}$ \\
\hline $\begin{array}{l}\text { Un sector público atrasado: raquitismo } \\
\text { presupuestario con una inadecuada com- } \\
\text { posición del gasto, sistema fiscal arcaico y } \\
\text { propensión al déficit y a su financiación al } \\
\text { margen de la disciplina de los mercados fi- } \\
\text { nancieros. }\end{array}$ & $\begin{array}{l}\text { La administración sigue pendiente de } \\
\text { profunda reforma que lo adecue a las ne } \\
\text { dades de una economía dinámica y flex } \\
\text { Insostenible económicamente, inefici } \\
\text { y desvirtuada la naturaleza funcionari } \\
\text { confluir una laxa normativa y una direc } \\
\text { cambiante y arbitraria. }\end{array}$ \\
\hline $\begin{array}{l}\text { Fuerte intervencionismo de los sectores cla- } \\
\text { ve de la economía: agricultura, industria, } \\
\text { combustibles, vivienda. Determinación de } \\
\text { precios y regulación de las importaciones y } \\
\text { exportaciones. }\end{array}$ & $\begin{array}{l}\text { Se encuentran intensamente subvenciona- } \\
\text { dos el sector del automóvil, energía y, sobre } \\
\text { todo la banca. Aumento de la normativa de } \\
\text { control en el sector financiero y aumento de } \\
\text { las medidas de control al sector público. }\end{array}$ \\
\hline
\end{tabular}

Fuente: (Miranda, 2001) y elaboración propia. 
España ha sido un país en el que tradicionalmente la industria ha tardado en despegar cuando los años precedentes había ralentizado, por unos motivos u otros, su marcha. Se constata la gran diferencia en los periodos de crecimiento de la industria española, en comparación con la de otros países. Así, mientras Alemania tardó en recuperar su nivel de industrialización tras el periodo bélico sólo cuatro años, o los 6 de Francia, en el caso de España no fue sino hasta 1952, esto es, 13 años después de finalizada la guerra civil, cuando el país recupera niveles de producción de la era prebélica. (Miranda, 2001). Si no fuimos capaces de rearmar con diligencia nuestra industria en tiempos de crecimiento económico, siquiera forzado, parece más complejo que en etapas de recesión como la actual, pueda producirse un giro de este sentido, al menos aplicando los recursos que tradicionalmente se habían aportado al sector secundario.

Aún más, durante el periodo autárquico y siguiendo al mismo autor, se constata que el crecimiento de la producción de bienes intermedios y bienes de inversión fue muy superior al experimentado por las industrias de bienes de consumo. De manera paralela, el aumento de la actividad en el denominado 'mercado negro' (Barciela, 1986) o (Ruiz, 2003) generó importantes desequilibrios en los precios en el mercado controlado por el Estado y el que afloraba, oculto, tras mostradores y almacenes furtivos al fisco y la inspección.

\section{Nuevos PaRAdigmas fundamentados EN El CONCEPTO AUtÁRQUico}

Realizadas las comparaciones entre ambos periodos, procedamos a contextualizar los datos para poder enfocar adecuadamente posiciones que permitan recoger prácticas del periodo autárquico, transmutarlas y valorar su aplicabilidad a partir de las experiencias aprendidas.

Las matizaciones que se deben plantear son las siguientes:

a) La diferencia de posición de partida: aun considerando la similitud cualitativa de los impactos de los hechos que singularizan cara periodo (guerra destructiva y crisis anuladora), en la actualidad disponemos de un valor como son los activos, tanto físicos como humanos con los que sí contamos, a diferencia tras la Guerra Civil. La capacidad de producción está prácticamente intacta, acometiendo un proceso de ajuste a la demanda, pero con recursos para acomodarse en el medio plazo a las necesidades del mercado. En el periodo postbélico la necesidad de reconstruir infraestructuras ralentizó el proceso de revitalización económica.

b) La imposibilidad de recurrir a una política monetaria como la del periodo autárquico y que, recordemos, se siguió utilizando hasta 1999, casi quince años después de la incorporación de nuestro país a la UE (entonces CE), tomar el control de la emisión de moneda y fijación de tipos de interés el Banco Central Europeo (UNED, 2005). Hasta ese momento 
la profusión de intervenciones monetaristas, especialmente en lo que concernía al tipo de cambio, salvó no pocas campañas de exportaciones españolas en general y del calzado o turismo en particular, incorporando un referente próximo.

c) El nivel de endeudamiento actual es, sencillamente, insoportable. La deuda pública creció en 2012 hasta los 882.300 millones de euros, cantidad equivalente aproximadamente al $84 \%$ del PIB (según fuentes oficiales, que contrastan con otras que lo sitúan en algo más del $110 \%$ ). En términos relativos, es el nivel de endeudamiento más alto en más de un siglo y el FMI y OCDE apuntan a que seguirá subiendo hasta 2015 En cuanto a la deuda privada, las empresas debían en el mes de marzo 1.140 billones de euros y las familias 829.643 millones de euros, de los que algo más de 638.000 corresponden a créditos hipotecarios y 187.000 a créditos al consumo.

d) El nivel de desempleo era y es ciertamente dispar, pero aún lo son más las perspectivas de ocupación. Si tras la Guerra Civil la mano de obra disponible no tardaba en ocuparse en casi cualquier sector (S.Reher, 2013), principalmente aquellos destinados a la reconstrucción del país y la regeneración de estructuras productivas, en la actualidad las opciones de empleabilidad distan mucho de ofrecer a los trabajadores la triada mágica: proximidad, seguridad y rentabilidad. Es más, mientras en la etapa postbélica, muchos de los trabajadores tuvieron que exiliarse (unos 300.000) y buscar en el extranjero una oportunidad laboral, en la actualidad son los jóvenes mejor formados los que buscan más allá de nuestras fronteras una oportunidad laboral que aquí se les niega. El dato más destructivo: el 57\% de los jóvenes está en desempleo. A principios de 2012 ya eran 300.000 quienes habían tenido que emigrar para buscar trabajo lejos de nuestras fronteras. Y casi dos millones de hogares tenían a todos sus miembros en paro.

e) La inflación española ha pasado a ser, en la actualidad, una variable moderada y acompasada a los tiempos de crisis. Pero no olvidemos que en 2010 su pertinaz crecimiento, acompañados de registros negativos del $\mathrm{PIB}$, nos retrotrajo a un término que parecía reservado a la teoría en los libros: la estanflación y a la que ahora de nuevo nos acercamos. En la actualidad, la economía nacional sigue registrando tasas de crecimiento negativas, en proceso que ya se arrastra desde el último trimestre de 2011. Por otro lado, el descenso del IPC en el pasado mes de noviembre, nos permite esbozar una ligera sonrisa, pero sólo eso. Lo cierto es que la pérdida de poder adquisitivo de los consumidores está obligando a las empresas a revisar y reducir sus precios si quieren mantener su nivel de ventas. No obstante, la futura Ley de Desindexación de la economía española, si de verdad provoca que la actualización de los contratos 
públicos, de los salarios de los empleados públicos y de las pensiones se haga por debajo del IPC puede ayudar a dar un nuevo impulso a la competitividad del país.

f) El sector público se encuentra en un punto de no retorno y a la espera de que quienes han de llevar a cabo una profunda reestructuración del mismo encuentren el momento de llevarla a cabo. Económicamente insostenible, plagada de duplicidades entre los distintos niveles administrativos y con una cobertura de servicios que no se corresponde con las asignaciones presupuestarias, por ejemplo con los ayuntamientos, que asumen las "competencias impropias", que ha motivado una parte no menor de las deudas municipales.

g) El mercado interior no está cerrado con regulaciones proteccionistas. Sin embargo, está vetado de facto por la caída de la renta disponible de las familias y las empresas, debido a la falta de crédito de un lado, y consecuencia u origen, del tremendo endeudamiento del país y donde los acreedores no ofrecen tregua. Una demanda creciente es la vitamina que toda economía capitalista necesita para evolucionar y esto ahora no es posible encontrarlo ni la revuelta alcoba doméstica ni en los mercados internacionales, conformes con comprar deuda estatal española a buen precio.

h) El intervencionismo es elemento común denominador a las actuaciones políticas de los últimos 20 años, bien vía ayudas y exenciones aplicadas para dinamizar sectores considerados estratégicos (automóvil, vivienda,..) pero cuya generalización devino en un modelo en el que prácticamente todo tenía que estar subvencionado (via oferta o demanda) para que resultara atractivo al comprador. La última etapa el alcance del intervencionismo ascendió a un grado impensable, esta vez externo, que ha supuesto desde la prolongación de la vida laboral, decretada a modo de garantía para los acreedores del Estado, la socialización de las pérdidas del sistema bancario, rescatado con la garantía del Estado, en un movimiento estratégico de los acreedores de España perpetrado a través de la UE. En los últimos meses ese intervencionismo ya afecta a políticas fiscales, de mercado de trabajo y de organización interna. Y no entramos a valorar en la conveniencia de las mismas.

i) No podemos olvidar los nefastos efectos que tan prolongado periodo de aislamiento tuvo en la economía española. Tal como indica (Ligero, 2005), dos de los factores perniciosos que afectaron gravemente a nuestro país fueron la pérdida de competitividad de nuestros productos, con la contrapartida de una escasa entrada de capital con origen en las exportaciones, pero sobre todo, el bloqueo a la entrada de importaciones, de especial importancia para el desarrollo del sector industrial, terminaron de bloquear nuestras ya de por sí exiguas opciones de crecimiento. 
3. REENFOQUE DE LAS POLÍTICAS LOCALES PARA FABRICAR LAS HERRAMIENTAS DE CRECIMIENTO PARA EL NUEVO MUNDO

Para la identificación de nuevas formas de intervención, es necesario revisar los fundamentos y potencialidades de los entes locales, referenciados a su papel como impulsores del crecimiento y desarrollo socioeconómico. Tomaremos como referencia la apuesta que realiza Sergio A. Berumen (A. Berumen, 2006) con relación a las fortalezas competitivas de las entidades locales, entre las que podemos destacar:

1. El concepto de espacio territorial ya no es un ámbito físico. Una entidad local domina su territorio en tanto en cuanto conoce, desde luego el territorio de su ámbito administrativo, pero también las relaciones, los intereses, los flujos de información. Las ciudades ya no son espacios de residencia, ocupación y tránsito viario donde los ciudadanos desarrollan las diferentes facetas de su vida, a modo de 'soporte que alguien tiene que coordinar' sino que ya se les exige que actúen promoviendo, captando, incentivando el crecimiento, las actividades socioeconómicas, el desarrollo en general. Los ciudadanos quieren que las ciudades sean proactivas, término que hasta la fecha sólo se habían referida a un comportamiento humano.

2. Un segundo factor es el que se refiere al concepto de "causalidad acumulativa" y que tiene en la incorporación de las nuevas tecnologías un factor acelerador de las ventajas competitivas generadas por el progreso tecnológico. Figuras tipo 'cluster' acumulan estos beneficios y obtienen ventajas de los mismos. Por lo tanto, facilitar esta acumulación de conocimientos y la transparencia de esta información será un factor importante a la hora de potenciar nuestros municipios.

3. La competitividad de un espacio regional de mayor o menor tamaño se asienta sobre la base de una cultura con mayor o menor propensión a incorporar la innovación y la forma en la que esta información se transmite. El introducir el factores que propicien la incorporación de elementos novedosos en las empresas, alentará a la introducción y posterior consolidación de un proceso transformador que se adoptará con total normalidad.

Resta por puntualizar un último elemento que resulta la piedra angular de la nueva economía: la competitividad de un territorio ya no es una cuestión puntual o fundamentada en factores competitivos asociados operativamente en un momento determinado: la verdadera competividad se consigue cuando una sociedad consigue articular un sistema de evolución continua que le permite mantenerse en primera línea de la eficiencia; es vincular, reconocer y operar en consecuencia y con naturalidad reconociendo la necesidad de adaptarse con proyecciones futuras que permitan tomar y anticipar las decisiones adecuadas 
para posicionarse siempre adecuadamente. Un símil deportivo sería entender que los territorios deben adoptar una cultura prospectiva, al igual que el jugador de ajedrez realiza movimientos óptimos para el momento de juego actual, pero también intuyendo las posibles estrategias del oponente. El jugador que es capaz de ver más jugadas futuras puede posicionarse y llevar la iniciativa. La clave es la anticipación.

$\mathrm{Y}$ es precisamente para poder encauzar adecuadamente las acciones que se lleven a cabo por lo que es necesario entender hacia dónde se orientan las políticas europeas en este sentido. Así, la Comisión Europea (Europea, 2010) establece tres prioridades para situar al Viejo Continente en el año 2020:

- Crecimiento inteligente: desarrollo de una economía basada en el conocimiento y la innovación;

- Crecimiento sostenible: promoción de una economía que utilice eficazmente los recursos, que sea verde y competitiva;

- Crecimiento integrador: fomento de una economía con un alto nivel de empleo que redunde en la cohesión económica, social y territorial.

Identificados tanto el punto de partida como el objetivo a alcanzar, se deberán plantear las opciones que permitan cumplir con estas finalidades. Por otro lado, y derivado de todo lo anteriormente tratado, del análisis comparativo del periodo postbélico y autárquico, de la observación de sus analogías y diferencias, de las líneas maestras esbozadas por la UE a largo plazo, así como de las matizaciones necesarias para equilibrar las acciones a proponer, resulta oportuno identificar las características de las medidas a proponer por las entidades locales en un contexto como el actual. De las cuestiones que se mencionan a continuación, considérense en cada caso, como recetas de extensión cortoplacista; los excesos en estos casos no son recomendables (Miranda, 2001). Estas singularidades se puntualizan en:

a) Características generales de la intervenciones:

a. Las EE.LL no deben ser meras prestadoras de servicios a demanda, sino que deben aportar y anticipar las necesidades de sus clientes/usuarios/ administrados. La prospección es una obligación de lo público frente a la inacción de la iniciativa privada, suficientemente agobiada por el corto plazo. Cuestión diferente es si las administraciones cuentan con los medios y recursos, cuantificados y cualificados para iniciativas de estas características.

b. La filosofía de las acciones que lleven las EE.LL deben promover y fomentar el asociacionismo 'útil', enfocado hacia la acumulación y transmisión de conocimiento, potenciando las sinergias entre empresas/ colectivos de un mismo sector o complementarios al mismo.

c. La difusión de una cultura permeable a la innovación (no a cualquier innovación, sino la innovación útil) obliga a adoptar nuevas metodologías 
de información y motivación para fomentar el interés por la novación de procesos y sistemas de producción o prestación de servicios.

b) Características singulares de las acciones a proponer por las EE.LL:

a. Frente a la imposibilidad de obtener recursos económicos para la adquisición de maquinaria o tecnología, surge la necesidad de potenciar y utilizar al máximo los activos disponibles en el territorio. El elemento más abundante es el conocimiento y el de los recursos humanos, en todas sus vertientes: mano de obra, conocimiento, importadores de habilidades,... Las empresas del futuro serán aquellas que agrupen la mayor cantidad de talento posible. Esto también implica plantear políticas de recuperación del talento fugado. Y se habla de recuperación puesto que, en puridad, aquellos que terminan sus estudios y no tienes posibilidad real de encontrar un trabajo que permita desarrollar su potencial, resulta lógico que busquen otros países donde su cualificación sea adecuadamente valorada; poco puede hacer la entidad local (incluso podría cuestionarse la conveniencia) de llevar a cabo políticas de retención, condenando a la persona al ostracismo laboral, cuando el trabajador puede adquirir una experiencia y conocimientos que posteriormente serán de gran utilidad a su retorno, trayecto que es el más difícil de conseguir.

b. La necesidad de favorecer la actividad monetaria en su comunidad. Y no me refiero a la 'masa monetaria', sino a la circulación, tráfico de dinero (o valor equivalente, en bienes o servicios, aquí está la clave) que genera dinamismo económico cuando pasa de unas manos a otras. El trabajo puede remunerarse de formas diferentes y aportando un valor de 'winwin' análogo al que puede ofrecer el dinero clásico.

c. Lucha sin cuartel contra el desempleo, pero sobre todo, contra el paro. Lo primero no depende en buena medida de nuestros recursos porque excede a nuestro ámbito competencial y capacidad como generadores de políticas efectivas. El segundo frente es diferente. Se puede estar desempleado, pero nunca permitir quedarse parado, inactivo, apocado. Si la filosofía que deben transmitir nuestras entidades es de favorecer una cultura de la anticipación, el dinamismo debe ser un factor común a todas las acciones que se realicen con los desempleados (ique no parados!), tratándoles de transfundir este concepto a su actitud frente a su situación. Siempre activos.

d. Es necesario dinamizar el mercado 'interior', el del propio municipio, frente a la dificultad de hacer crecer el público objetivo, esto es, si el mercado no puede generar mayor demanda, concentrémonos en conseguir más clientes de entre ese colectivo limitado. Buena parte de esta dinamización va a tener mucho que ver con la transparencia del mercado y la información que los usuarios (tanto demandantes como oferentes) 
dispongan del mismo, así como la confianza que tengan en el funcionamiento general del sistema. Como comentábamos la economía en no pocas ocasiones "depende de un estado de ánimo" ( (J.Shiller, 2009).

e. El intervencionismo del sector público a través de sus entidades locales, entiendo, es ahora más necesario que nunca. Pero se trata de un intervencionismo planificado, articulado y destinado a generar las condiciones para que se produzca riqueza y en la medida de lo posible, creación de empleo; no invasivo. Y con fecha de inicio y fin de las actuaciones. Un intervencionismo que contribuya a modular el mercado local, a darlo a conocer, a formar mejor e informar a los usuarios sobre los valores y activos del territorio para aprovechar el máximo posible del mismo. No son necesarios complejos planes de crecimiento. Pautas básicas conocidas por los agentes del territorio y en base a las cuales realizan sus previsiones, dentro de un marco de seguridad estratégica derivada del necesario acuerdo entre los distintos colectivos afectados (empresarios, partidos políticos, sindicatos, autónomos, desempleados,...).

f. Se debe intervenir para redefinir y hacer entender a nuestros clientes el concepto de estabilidad laboral (aunque quienes nos dedicamos a la función pública no seamos, quizá, los más adecuados para plantear esta materia): el nuevo concepto de 'seguridad en el trabajo', estará basado en la pluralidad de clientes y en la especialización. Esto obligará a articular sistemas precisos de comunicación para que demanda y oferta se encuentren adecuada y ágilmente. Esta flexibilidad ya la enunciaba Gabino Ponce (Herrero \& Martínez Puche (Coordinador), 2001), al indicar que "la especialización flexible de los sistemas productivos aparece como una solución válida", refiriendo la importancia de contar con estructuras ligeras, descentralizadas y recurriendo a la subcontratación, como vía de ajuste de costes.

g. Es el momento, igualmente, de aprovechar las sinergias entre todos los actores el territorio. Deberíamos cuestionarnos si en la situación actual, una entidad local debe dedicarse a sectores que ya ocupan otras entidades, públicas o privadas. Una entidad local debería centrarse en realizar labores de coordinación y de ordenación de los recursos que hay en su territorio, visibilizándolos al máximo. Esto propiciará un mayor uso de los activos del territorio y una especialización por parte de los distintos agentes, redirigiendo a los usuarios a los especialistas en cada área.

\section{Conclusiones}

Sería posible abordar con mayor profundidad y detalle las características de las políticas locales, tomando como referencia las experiencias del modelo autárquico. No es ésta la finalidad de este trabajo, orientado a sobrevolar por 
los aspectos básicos de un proceso comparativo entre dos etapas, autárquica y crisis actual, análogas en la evolución de algunas de sus variables económicas, totalmente dispares en muchos de sus orígenes. Ciertamente se trata de un estudio dirigido a plantear una reflexión en el lector, acerca de la información que nos puede aportar la revisión de experiencias pasadas para aprender lecciones de futuro.

Sorprende ver la similitud de elementos que comparten ambos periodos; pérdida de mano de obra, crisis del sector público, colapso del mercado interno, afloramiento de la economía sumergida o un fuerte intervencionismo en distinto sectores estratégicos.

De las lecciones aprendidas de aquel periodo hemos entendido la necesidad de activar los mercados interiores, a encontrar una justificación para potenciar el talento de las personas, a valorar la importancia de una administración activa, previsora, a avanzar para evitar el intervencionismo sectorial,... Todo ello con las cautelas propias que aconsejan que aquellas políticas que modulen la actividad en el territorio deben aplicarse sólo por el tiempo necesario, para evitar desvirtuar el mercado e incurrir en un improbable e indeseable proceso de pérdida de competitividad.

Quienes creemos firmemente en el desarrollo local, y hago ahora acopio de algunos de los principios de intervención antes indicados, debemos apostar por imprimir un cambio radical a nuestras intervenciones, enfocándolas hacia nuestros clientes/usuarios, contribuyendo a la optimización de los recursos del territorio evitando solapamientos para ser un servicio verdaderamente eficiente.

\section{BibLIOGRAFÍA}

A. BERUMEN, S. (2006). Competitividad y desarrollo local. Madrid: ESIC.

BARCIELA, C. (1986). El mercado negro de productos agrarios en la posguerra, 1939-1953. Alicante: J. Fontana.

EUROPEA, C. (2010). Europa 2020.Una estrategia para un crecimiento inteligente, sostenible e integrador. . Bruselas: Comisión Eurepea.

HERRERO, G. P., \& MARTÍNEZ PUCHE, A. (Coordinador) (2001). Impacto de la organización postfordista del trabajo en las comarcas alicantinas. Alicante: Textos Docentes (Universidad de Alicante).

J. SHILLER, G. A. (2009). Animal Spirits. Barcelona: Gestión 2000.

LIGERO, A. R. (2005). La política comercial española de la autarquí a la plena integración en el comercio multilateral. Política comercial española, 179.

LOCALES, U. D. (2009). El impacto de la crisis mundial sobre los gobiernos locales. Barcelona: UCL.

MIRANDA, J. A. (2001). El fracaso de la reindustrialización autárquica. Alicante: Departamento de Economia Aplicada. Universidad de Alicante.

PORTER, M. (1990). The competitive advantage of nations. New York: Free Press. 
RUIZ, E. M. (2003). El sector exterior durante la autarquía. Una reconstrucción de las balanzas de pagos de España (1940-1958). Madrid: Servicio de estudios del Banco de España.

S. REHER, D. (2013). Mercado de trabajo y empleo en España en el siglo XX. Recuperado el 02 de 05 de 2013, de Grupo de estudios Población y Sociedad: http://www.geps.es/uploads/tx_geps/030_Mercado_de_trabajo_y_empleo_en_EspanaSXX.pdf

UNED. (2005). La política monetaria en España. El contexto europeo. http:// www.uned.es/experto-dinero-banca/trabajos/La_politica_monetaria_Espana.pdf, Madrid. 